\title{
Indoor Nitrogen Oxides Occurrence, Modeling and
} Prediction

\author{
Ingrid Senitkova \\ Faculty of Mechanical Engineering, Technical University of Kosice, Letna 9, Kosice 04200, Slovakia
}

\begin{abstract}
Outdoor air quality, building materials, HVAC (Heating, Ventilation, Air Conditioning) systems and people activity are important factors in human exposition of polluted indoor air. The degree of signification varies in dependence on pollution character and its sources. Buildings eliminate significantly people exposition of outdoor pollutants, but on the other hand, buildings are significant source of indoor pollution. The contamination of indoor air is largely from the use of gas for heating and cooking appliances. A comprehensive analysis of indoor air pollution by nitrogen oxides shows that the extent of indoor air pollution and consequent exposure varies as a result of many factors mainly the differing distribution of appliances and their level of use. This study aims to formulate a mathematical model for the production of nitrogen oxides indoors. The physical processes that determine the concentrations of indoor nitrogen oxides as a function of outdoor concentrations, indoor emission rates and building characteristics have been mathematically described. The mathematical model developed has been parameterized for typical Slovak residences. The modeling of the occurrence of indoor nitrogen oxides and verification of the model is presented in this paper.
\end{abstract}

Key words: Indoors, nitrogen oxides, occurrence, prediction, modeling, verification.

\section{Introduction}

$\mathrm{NO}$ (Nitrogen monoxide) and $\mathrm{NO}_{2}$ (nitrogen dioxide) are gases produced by high temperature combustion through reactions between nitrogen and oxygen. Both nitrogen in the fuel and nitrogen in the air can participate in the reactions. Formation of $\mathrm{NO}$ can be followed by further oxidation into $\mathrm{NO}_{2}$ in the atmosphere. $\mathrm{NO}_{2}$ is the most toxic of the nitrogen oxides (grouped generically as $\mathrm{NO}_{\mathrm{x}}$ ) and it is very important from the health point of view. During several last years the emissions of nitrogen oxides have increased. The mean daily outdoor nitrogen oxides concentrations achieve value $107.1 \mu \mathrm{g} \cdot \mathrm{m}^{-3}$ in the winter and $35.2 \mu \mathrm{g} \cdot \mathrm{m}^{-3}$ in the summer. The mean daily indoor nitrogen oxides concentrations achieve value 125.3 $\mu \mathrm{g} \cdot \mathrm{m}^{-3}$ in the winter and $48.5 \mu \mathrm{g} \cdot \mathrm{m}^{-3}$ in the summer [1]. The most important indoor source of nitrogen oxides is gas burning in the kitchen. Finally concerning to indoor

\footnotetext{
Corresponding author: Ingrid Senitkova, $\mathrm{PhD}$, professor, research field: indoor sciences. E-mail: ingrid.senikova@tuke.sk.
}

environment, indoor air can be contaminated by using gas for heating and cooking and this probably involves a certain health hazard. Practical experiences show, that range of indoor nitrogen oxides concentration depends on energy conservation tendency interpret with ventilate level decrease [2]. The highest nitrogen oxides concentrations are achieved during gas burning in the kitchen in dependence on intensity of gas burning, amount of gas burned and on room disposition [3]. In the present work indoor $\mathrm{NO}_{\mathrm{x}}$ concentrations were measured in order to understand their contribution to indoor sources and so to human exposure.

\section{Indoor and Outdoor $\mathrm{NO}_{\mathrm{x}}$ Occurrence during the Year}

Indoor sciences have been studied over the last twenty years at Technical University of Košice in Slovakia. Initially the monitoring of indoor pollutants (radon, particles, VOCs, odours, nitrogen oxides, etc.) was undertaken in buildings located in the east part of Slovakia. Seasonal differences in pollutant levels were 
confirmed. It was shown that for this study which looked at indoor $\mathrm{NO}_{\mathrm{x}}$ concentrations were significantly higher than outdoor ones especially in the winter period (Fig. 1). All buildings studied used gas appliances, mainly in the kitchens [4].

\section{Method of $\mathrm{NO}_{\mathrm{x}}$ Concentration Measurement}

Measurements were made to detail $\mathrm{NO}_{\mathrm{x}}$ production and determine the resultant indoor concentrations while gas appliances were being used. The intensity of gas combustion varied in the range $0.1 \mathrm{~m}^{3} \cdot \mathrm{h}^{-1}-0.7$ $\mathrm{m}^{3} \cdot \mathrm{h}^{-1}$. As kitchens had been identified as the most polluted rooms measurements were taken in the kitchens. The levels of background concentrations of $\mathrm{NO}, \mathrm{NO}_{2}$ and $\mathrm{NO}_{\mathrm{x}}$ were monitored. The increase and decrease of $\mathrm{NO}_{\mathrm{x}}$ concentrations was found at the same time.

The investigation included online gas measurement for $\mathrm{NO}, \mathrm{NO}_{2}$ and $\mathrm{NO}_{\mathrm{x}}$ by the "Thermo Environmental Instruments Inc. - model 42 - Chemiluminiscence $\mathrm{NO}-\mathrm{NO}_{2}-\mathrm{NO}_{\mathrm{x}}$ Analyzer". This analyzer was located in the middle of the room, at the level of the breathing zone of a sitting person $-105 \mathrm{~cm}$ above the floor. The results showed concentration peaks during the cooking, but with large differences from using different intensities of gas burning.

\section{Results}

The concentrations of $\mathrm{NO}_{\mathrm{x}}$ after $1 \mathrm{~h}$ gas combustion were shown to depend on the level of gas consumption ranging from $0.1 \mathrm{~m}^{3} \cdot \mathrm{h}^{-1}$ to $0.7 \mathrm{~m}^{3} \cdot \mathrm{h}^{-1}$ (Fig. 2).

The changes in $\mathrm{NO}_{\mathrm{x}}$ concentration over the intensity range of gas consumption $\left(0.1 \mathrm{~m}^{3} \cdot \mathrm{h}^{-1}\right.$ to $\left.0.7 \mathrm{~m}^{3} \cdot \mathrm{h}^{-1}\right)$ were studied. The changes while allowing the combustion process to continue at maximum for 60 min, and for decreasing rates of gas usage, were then followed over the next 90 min after combustion had stopped. The pattern of oxides formation at a gas usage rate of $0.1 \mathrm{~m}^{3} \cdot \mathrm{h}^{-1}$ is given in Fig. 3. It is evident that an essentially linear increase of $\mathrm{NO}, \mathrm{NO}_{2}$ and $\mathrm{NO}_{\mathrm{x}}$ concentrations occurred during the whole combustion

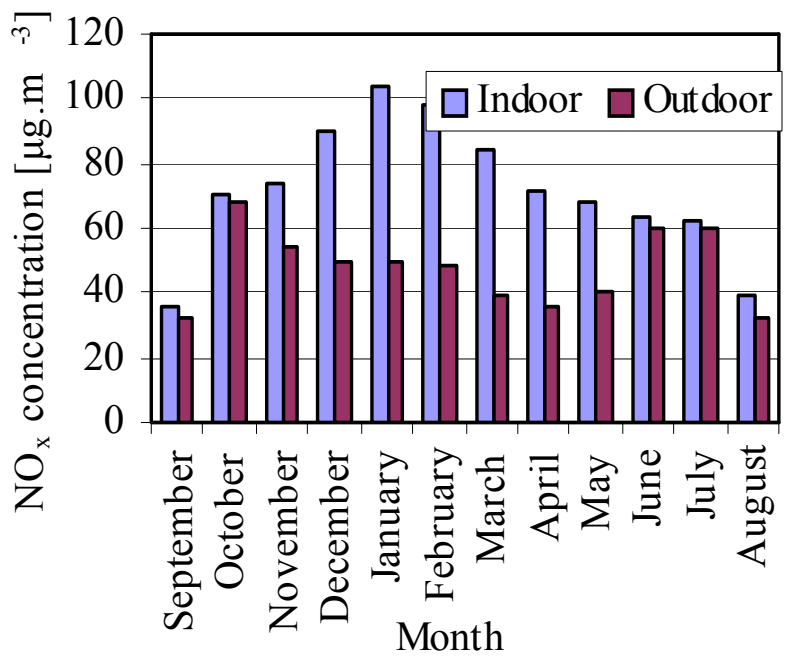

Fig. 1 Mean indoor and outdoor $\mathrm{NO}_{\mathrm{x}}$ concentrations throughout a year.

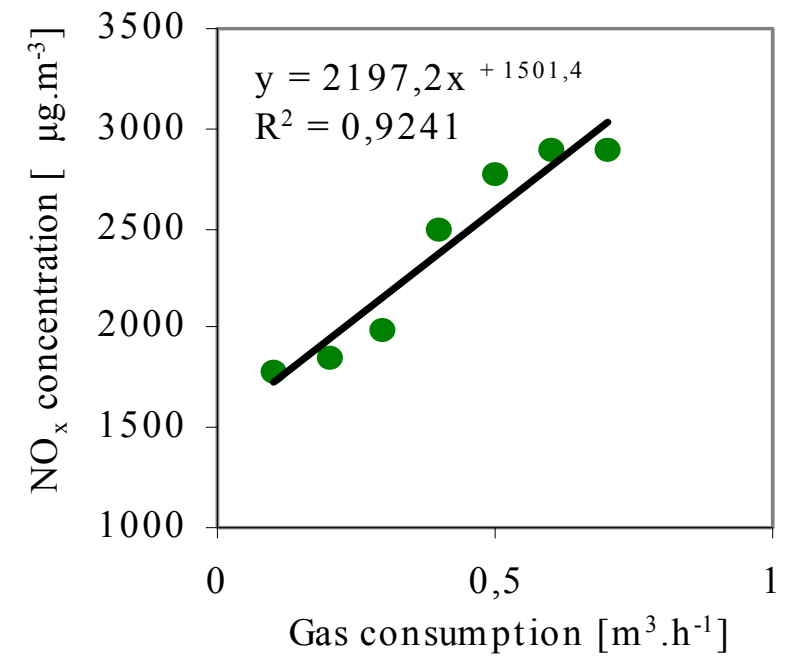

Fig. 2 The $\mathrm{NO}_{\mathrm{x}}$ concentrations for gas consumption range studied.

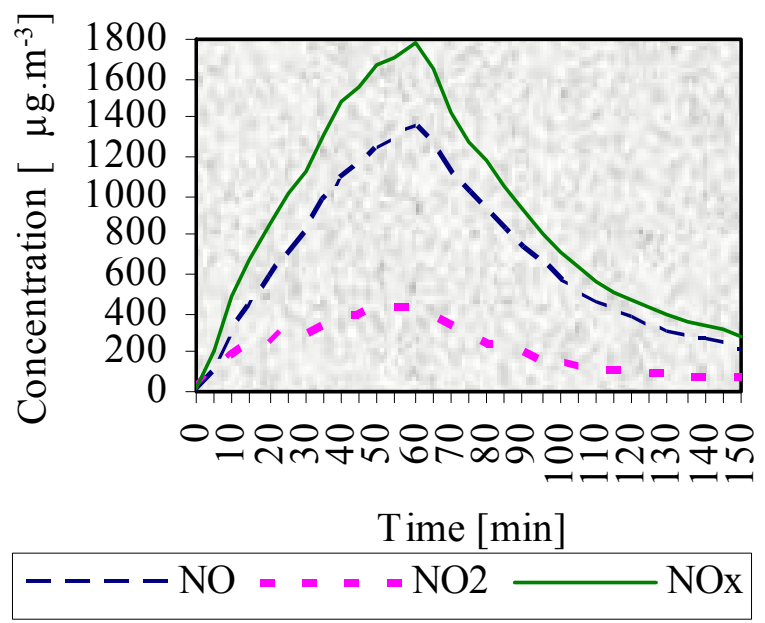

Fig. 3 The concentrations of nitrogen oxides at gas usage rate of $0.1 \mathrm{~m}^{3} \cdot \mathrm{h}^{-1}$. 
period to a final maximum value after $1 \mathrm{~h}$ when gas usage was stopped ( $\mathrm{NO} 1,357.4 \mu \mathrm{g} \cdot \mathrm{m}^{-3}, \mathrm{NO}_{2} 428.5$ $\mu \mathrm{g} \cdot \mathrm{m}^{-3}$ and $\left.\mathrm{NO}_{\mathrm{x}} \quad 1,785.9 \mu \mathrm{g} \cdot \mathrm{m}^{-3}\right)$. Decrease in concentration was then followed for a period of $90 \mathrm{~min}$, after which period the concentrations were NO 209.8 $\mu \mathrm{g} \cdot \mathrm{m}^{-3}, \mathrm{NO}_{2} 69.4 \mu \mathrm{g} \cdot \mathrm{m}^{-3}$ and $\mathrm{NO}_{\mathrm{x}} 279.1 \mu \mathrm{g} \cdot \mathrm{m}^{-3}$.

Importantly, it should be noticed that the concentration of $\mathrm{NO}_{2}$ after $1 \mathrm{~h}$ of gas combustion $\left(428.5 \mu \mathrm{g} \cdot \mathrm{m}^{-3}\right)$ more than exceeded double the limit value according to the Slovak standard $\left(200 \mu \mathrm{g} \cdot \mathrm{m}^{-3}\right)$. The limit was exceeded after $10 \mathrm{~min}$ from the start of combustion $\left(270.9 \mu \mathrm{g} \cdot \mathrm{m}^{-3}\right)$ and concentrations remained above the limit for the next $100 \mathrm{~min}$ (228.6 $\left.\mu \mathrm{g} \cdot \mathrm{m}^{-3}\right)[5]$.

\section{Mathematical Modeling}

Designing and modeling can substantially contribute to problem solution and to obtaining new understanding concerning system behavior with respect to air component dynamic changes. A mathematical description of the processes can generalize the experimental results and so they may be used to interpret other processes physically similar to those introduced in the model.

Although modeling doesn't achieve all the rules of similarity, it does provide overall information concerning systems' behavior, which is only a little different from a real situation. Also, although it is an approximation the model does simplify description of the real physical measurements.

\subsection{Prediction of $\mathrm{NO}_{x}$ Occurrence}

The difficulty of predicting $\mathrm{NO}_{\mathrm{x}}$ emissions during combustion of fossil fuels is caused mostly by the complexity of the mechanisms of formation of the $\mathrm{NO}_{\mathrm{x}}$, which depend on many factors. Some partial mechanisms have not been completely clarified so far and so it is not possible to describe them exactly. In consequence, empirical correlations between the fuel properties, combustion regime and $\mathrm{NO}_{\mathrm{x}}$ emissions cannot be properly calculated. This affects the degree to which calculations can be informative in a mathematical model of indoor $\mathrm{NO}_{\mathrm{x}}$ production. The final result has to be assembled from the results obtained from statistically suitable collections of measurements as well as more controlled laboratory measurements [5].

\subsection{Input Parameters}

The research task to describe $\mathrm{NO}_{\mathrm{x}}$ production in combustion process relies on the measure of $\mathrm{NO}_{\mathrm{x}}$ influenced by such parameters which directly characterize the combustion process, i.e., intensity of gas combustion $I\left(\mathrm{~m}^{3} \cdot \mathrm{s}^{-1}\right)$, exposure period $t(\mathrm{~s})$, amount of indoor air $m(\mathrm{~kg})$ and air change $n\left(\mathrm{~s}^{-1}\right)$.

All the given variables are defined using basic dimensions, allowing their direct use for dimensional analysis to create the mathematical model of $\mathrm{NO}_{\mathrm{x}}$ production. All the variables can be simply measured directly during combustion allowing us subsequently to compare the $\mathrm{NO}_{\mathrm{x}}$ production under particular working conditions on the chosen combustion device on the basis of direct measurements and by means of the created mathematical model described in the following section [6].

\subsection{Dimensional Analysis Application}

The mathematical model describing $\mathrm{NO}_{\mathrm{x}}$ formation is based on the formation of dimensionless arguments, $\pi_{i}$, from the stated variables that influence formation of the oxides of nitrogen. The valuable property of these arguments is that in all existing systems of units they have the same numerical size and they have no dimension.

Formation of a mathematical model rests on derivation of functional dependence from the expressed dimensionless variables, which in general always has exponential character. Transformation of this function into logarithmic co-ordinates corresponds to a linear character that makes the work with the model easier and enables one to determine simply the parameters of linear function. 
The model given here has universal validity for all combustion devices that have at least approximately similar geometric characteristics. For every combustion device the parameters of linear function, i.e., regression coefficients, have to be determined separately.

The mathematical formula of nitrogen oxides production by application the dimensional analysis is [4]:

$$
N O_{x i}=10^{9} \cdot A \cdot t^{B-} n^{B} \cdot m \cdot I^{-1}
$$

where, $A$ and $B$ are regression coefficients calculated by the method of least squares.

$$
N O_{x}=N O_{x o}+N O_{x i}
$$

where,

$N O_{x I}$-indoor nitrogen oxides concentration;

$\mathrm{NO}_{x 0}$ - outdoor nitrogen oxides concentration.

Eq. (2) presents a mathematical model of $\mathrm{NO}_{\mathrm{x}}$ production through using gas appliances in the kitchen [4].

\section{Verification of Mathematical Model}

The mathematical model was verified for various amounts of gas consumption in the range of 0.1-0.7 $\mathrm{m}^{3} \cdot \mathrm{h}^{-1}$. As illustration verification for gas consumption of $0.1 \mathrm{~m}^{3} \cdot \mathrm{h}^{-1}$ using a model experimental room is given below. The amount of air was $28.28 \mathrm{~kg}$ and the air change rate $3.56 \times 10^{-4} \mathrm{~s}^{-1}$. The air change rate was determined on the basis of decreasing $\mathrm{NO}_{\mathrm{x}}$ concentration per hour.

On the basis of measured input parameters, $\mathrm{NO}_{\mathrm{x}}$ concentrations were determined through the located constants and regression coefficients obtained by the method of least squares. These values are presented in the Table 1.

The relationship for $\mathrm{NO}_{\mathrm{xi}}$ production at a gas consumption rate of $0.1 \mathrm{~m}^{3} \cdot \mathrm{h}^{-1}$ is obtained from:

$$
N O_{x i}=\frac{4.0 E-09 \cdot t^{1.8420-1} \cdot n^{1.8420} \cdot m}{I}
$$

The values of measured and calculated NOx concentrations are compared in Table 2 . The differences
Table 1 Regression coefficient values.

\begin{tabular}{lll}
\hline Gas consumption & $\mathrm{A}\left(\mathrm{m}^{3} \cdot \mathrm{h}^{-1}\right)$ & $\mathrm{B}\left(\mathrm{m}^{3} \cdot \mathrm{h}^{-1}\right)$ \\
\hline 0.1 & $4.0000 \mathrm{E}-09$ & 1.8420 \\
0.2 & $2.0000 \mathrm{E}-08$ & 1.7765 \\
0.3 & $2.0000 \mathrm{E}-07$ & 1.8179 \\
0.4 & $3.0000 \mathrm{E}-07$ & 1.8593 \\
0.5 & $4.0000 \mathrm{E}-07$ & 1.6603 \\
\hline
\end{tabular}

Table 2 The measured and calculated $\mathrm{NO}_{\mathrm{x}}$ concentrations.

\begin{tabular}{cccl}
\hline $\mathrm{T}(\mathrm{min})$ & $\begin{array}{l}\mathrm{NO}_{\text {xmeas.mean }} \\
\left(\mu \mathrm{g} \cdot \mathrm{m}^{-3}\right)\end{array}$ & $\begin{array}{l}\mathrm{NO}_{\text {xcalc }} \\
\left(\mu \mathrm{g} \cdot \mathrm{m}^{-3}\right)\end{array}$ & $\begin{array}{l}\text { Deviation } \\
(\%)\end{array}$ \\
\hline 5 & 204.7 & 243.9 & 20.67 \\
10 & 489.5 & 420.6 & 16.34 \\
15 & 671.5 & 583.2 & 16.97 \\
20 & 854.5 & 737.3 & 19.54 \\
25 & $1,013.0$ & 885.4 & 18.43 \\
30 & $1,131.8$ & $1,028.9$ & 17.10 \\
35 & $1,320.8$ & $1,168.6$ & 13.89 \\
40 & $1,477.9$ & $1,305.1$ & 12.15 \\
45 & $1,565.1$ & $1,439.0$ & 10.77 \\
50 & $1,660.9$ & $1,570.5$ & 10.02 \\
55 & $1,711.7$ & $1,700.0$ & 11.53 \\
60 & $1,785.9$ & $1,827.7$ & 11.25 \\
\hline
\end{tabular}

between measured and calculated $\mathrm{NO}_{\mathrm{x}}$ concentrations are considered acceptable. They can be explained, in that the selection of relevant parameters is a simplification, their degree of involvement and how many of all the factors on which $\mathrm{NO}_{\mathrm{x}}$ production depends they represent is unknown.

\section{Conclusions}

The study of indoor pollutants affecting indoor air quality is a modern problem. One solution is the use of mathematical methods to predict the level of pollutant concentrations. This paper proposes a possible mathematical approach to modeling the occurrence of $\mathrm{NO}_{\mathrm{x}}$ indoors. Correct selection and clear determination of all relevant parameters at the beginning of construction of the mathematical model are important. Through comparison with experimental measurements we have confirmed that $\mathrm{NO}_{\mathrm{x}}$ production is mainly affected by intensity of gas combustion, exposure period, and rate of air change. A mathematical description of the physical processes influencing $\mathrm{NO}_{\mathrm{x}}$ 
production has been derived and used to predict occurrence of these gases.

The model was verified with satisfactory results for gas consumption in the range 0.1-0.7 $\mathrm{m}^{3} \cdot \mathrm{h}^{-1}$. Differences between measured and calculated indoor $\mathrm{NO}_{\mathrm{x}}$ concentrations are probably because the selected relevant variables for construction of the mathematical model do not give a complete and exactly true picture of the combustion processes leading to $\mathrm{NO}_{\mathrm{x}}$ production. Results from the mathematical modeling approach can be improved thorough better understanding of precise input parameters which will make the process applicable to building design and building management.

\section{Acknowledgments}

This article was written as a national projects solution. The author is grateful to the Slovak Grant Agency for supporting of the projects, mainly project No 064 TUKE-4/2011.

\section{References}

[1] I. Senitkova, Nitrogen Oxides, in: Indoor Pollutants with Negative Health Impact, Slovak Ministry of Building Industry, Zing Print Press, Bratislava, 1999, p. 168.

[2] R. Kralikova, M. Badida, Environmental Engineering Technics, SjF TU Kosice, Elfa, Kosice, 2007, p. 303.

[3] I. Senitkova, S. Zimermannova, M. Carnogurska, Indoor air toxicology-nitrogen oxides study, in: Proceedings of the 5th Conf. on Environment and Mineral Processing, Technical University Press, Ostrava, 2000, p. 6.

[4] I. Senitkova, M. Carnogurska and S. Zimermannova, Ambient air influence on indoor air quality, in: Proceeding of the 4th Conf. Environmental problems of cities, Expo-Educ Press, Kosice, 2001, p. 6.

[5] I. Senitkova and M. Carnogurska, Mathematical model of NOx Production, in: Proceeding of the 6th Conf. Current Issues of Cicil and Environmental Enginering, Lviv, 2001, pp. 168-172,

[6] I. Senitkova, S. Vilcekova, Prediction of indoor nitrogen oxides concentration, in: Proceeding of the 9th Intern. Conf. on Indoor Air Quality and Climate: Indoor Air 2002, Monterey, Santa Cruz, 2002, pp. 286-291. 